\title{
Wound Dressing Techniques and Costs at a County Hospital
}

\author{
Pamela Amatta Odhiambo, Kennedy Omondi, Ng'wena Magak
}

School of Medicine, Maseno University

Correspondence to: Pamela Amatta Odhiambo, PO Box 3838-40100 Kisumu, Kenya; email: amatta19@gmail.com

\begin{abstract}
Background: Wound management is one of the commonest procedures conducted in surgical departments across health facilities in Kenya. Objective: This study aimed at exploring wound dressing techniques used at Migori County Referral Hospital (MCRH) and the cost of treatment to patients. Methods: Convenience sampling was used to select inpatients presenting with wounds undergoing treatment at the time of recruitment. Five patients ( 2 male and 3 female) were enrolled after obtaining informed consents. Wounds were examined during cleaning and dressing and healing process follow-ups made. Selection of wound dressing technique was done by the primary clinicians with no bias from the research team. Results: One patient's wound was an open fracture resulting from a road traffic accident; three patients had pyomyositis following thorn pricks; and the last patient's was sustained following a blast injury. Wound management methods employed at MCRH included cleaning
\end{abstract}

with vinegar, irrigation with normal saline, dressing with honey, and improvised negative pressure wound therapy. Total cost incurred was affordable to patients, and ranged between Kenya shillings 100-360 (USD 1-3.60) weekly. Conclusion: Wound management techniques at MCRH were effective and affordable. Additional studies with a larger sample size are recommended.

Key words: Wound dressing, costs, NPWT, vinegar cleaning, honey dressing

Ann Afr Surg. 2019; 16(1):33-37

DOI: http://dx.doi.org/10.4314/aas.v16i1.8

\section{Conflicts of Interest: None}

Funding: None

(C) 2019 Author. This work is licensed under the Creative Commons Attribution 4.0 International License.

with pre-existing diabetes mellitus or peripheral vascular disease were excluded. History, biodata and examination findings were documented. The techniques applied for wound dressing were observed and documented progressively until the patients were discharged from hospital. Estimates of daily and cumulative cost of the dressing materials were generated. Quantitative data are presented as tables while the techniques are described qualitatively. Ethical clearance and permission to conduct the study were obtained from the medical superintendent's office.

\section{Results}

Nine patients were admitted at MCRH with various wounds; of these four were excluded, leaving two males and three females. Table 1 shows the demographic and clinical profiles of the patients studied.

\section{Wound Dressing Techniques Used}

Improvised negative pressure wound therapy

Negative pressure wound therapy (NPWT) was applied after initial surgical debridement on a patient with a degloving wound on the palmar aspect of the right hand following 
Table 1: Patient demographics and wound care methods

\begin{tabular}{|c|c|c|c|c|c|c|}
\hline $\begin{array}{l}\text { Study } \\
\text { code }\end{array}$ & Age (yrs) & Sex & $\begin{array}{l}\text { Days to } \\
\text { presentation }\end{array}$ & Other risk factors & Wound dressing method used & $\begin{array}{l}\text { Presence of } \\
\text { complications }\end{array}$ \\
\hline MGR001 & 14 & $\mathrm{~F}$ & 6 & Presented a week later & NPWT and honey dressing & None \\
\hline MGR002 & 75 & $\mathrm{~F}$ & 2 & $\begin{array}{l}\text { Elderly; initially had pyomyositis } \\
\text { which then developed into an } \\
\text { open wound }\end{array}$ & Vinegar and honey dressing & None \\
\hline MGR003 & 45 & $\mathrm{~F}$ & 0 & Obesity & $\begin{array}{l}\text { Irrigation with normal saline } \\
\text { and honey dressing }\end{array}$ & Yes (open fracture) \\
\hline MGR004 & 39 & M & 2 & $\begin{array}{l}\text { Initially had pyomyositis which } \\
\text { then developed into an open } \\
\text { wound }\end{array}$ & lodine & None \\
\hline MGR005 & 28 & M & 0 & None & Irrigation with normal saline & None \\
\hline
\end{tabular}

explosion of an unknown device. Materials used included sterile gauze pad, normal saline $(250 \mathrm{~mL})$, natural honey $(8 \mathrm{~mL})$ and one tubal end of a urine bag.

Three layers of gauze were created. A piece of sterile gauze soaked in normal saline was applied on the wound bed. Next was a layer of a piece of dry gauze to cover all parts of the first layer while ensuring there was no contact with intact skin. The third layer consisted of gauze with a thin layer of honey. This was covered with a piece of dry gauze. The endtube of a sterile urine bag was then placed on the top layer of gauze and covered with dry gauze. The entire dressing was sealed with cling film and secured using zinc oxide strapping. Next, the other end of the tube was connected to the suction machine set at $-95 \mathrm{mmHg}$.

The dressing was changed at 24, 48 and 96 hours post application. A second debridement was performed on day 4 , followed by subsequent dressing every third day.

\section{Use of vinegar and honey}

One patient with a wound on the dorsum of the foot following debridement for pyomyositis had the wound dressed with vinegar and honey. Materials required were one part vinegar $(15 \mathrm{~mL})$ mixed with two parts normal saline $(30 \mathrm{~mL})$. This mixture was used to clean the wound, followed by dressing with a thin layer of gauze secured in place by zinc oxide strapping. This was repeated every day for six consecutive days. Prior to each dressing, the wound was soaked in warm water for about 30 minutes.

\section{Irrigation with normal saline and honey}

Irrigation with normal saline and honey was applied to a patient with an open fracture of the distal third of the tibia. The wound was soaked in warm normal saline for approximately 30 minutes. It was irrigated with normal saline to wash off any loose debris and dead tissue until spontaneous bleeding was noted from the wound surface.
Bleeding was controlled by applying pressure and a dressing soaked in honey. The dressing was covered with dry gauze and secured along the edges.

\section{Use of oodine}

Iodine was used on a patient with pyomyositis secondary to a thorn prick, resulting in an open wound following debridement. The wound was cleaned with normal saline, as described above. Iodine solution $(10 \mathrm{~mL})$ was placed on gauze, applied on the wound surface and left to dry.

\section{Irrigating with normal saline}

The wound was cleaned as described above and then covered with a thin sheet of moist gauze. The gauze was strapped at the edges to keep it in place.

\section{Cost incurred by patients for various wound dressing techniques}

Table 2 shows the unit cost of the various dressing techniques, which range from USD 1 to 3.60 (Table 2).

\section{Discussion}

Several techniques were used to dress wounds at the MCRH. Wet to dry dressing is not encouraged because it causes wounds to dry out, leading to bleeding and destruction of the healing layer of tissue when the dressings are changed, which eventually slows the healing process (6).

NPWT uses continuous or intermittent sub-atmospheric pressure applied directly to a wound bed to assist healing (7). The optimal pressure to be used is approximately -125 $\mathrm{mmHg}$, using an alternating pressure cycle of 5 minutes of suction followed by 2 minutes off suction (8). This method works by optimizing blood supply to the wound area and decreasing local and peripheral tissue edema; the reduced edema then leads to rapid cell regeneration and proliferation in the wound (9). NPWT also reduces bacterial biofilm on 
Table 2: Costs incurred by the patients (KES 100 to USD 1)

\begin{tabular}{|c|c|c|}
\hline \multirow[b]{2}{*}{ Wound dressing technique / Materials used } & \multicolumn{2}{|c|}{ Material cost } \\
\hline & KES & USD \\
\hline \multicolumn{3}{|l|}{ Negative pressure wound therapy } \\
\hline Normal saline (500 mL) & 50.0 & 0.50 \\
\hline $\begin{array}{l}\text { Gauze (8 small packs): dressing pack with } \\
\text { gauze, strapping }\end{array}$ & 50.0 & 0.50 \\
\hline Cling film (lasts for 2 weeks) & 135.0 & 1.35 \\
\hline Honey & 125.0 & 1.25 \\
\hline Total cost & 360.0 & 3.60 \\
\hline \multicolumn{3}{|l|}{ Honey dressing } \\
\hline Normal saline $(500 \mathrm{~mL})$ & 50.0 & 0.50 \\
\hline $\begin{array}{l}\text { Gauze ( } 8 \text { small packs): dressing pack with } \\
\text { gauze, strapping }\end{array}$ & 50.0 & 0.50 \\
\hline Honey & 125.0 & 1.25 \\
\hline Total cost & 225.0 & 2.25 \\
\hline \multicolumn{3}{|l|}{ Irrigation with normal saline } \\
\hline Normal saline (500 mL) & 50.0 & 0.50 \\
\hline Total cost & 100.0 & 1.00 \\
\hline \multicolumn{3}{|l|}{ lodine application } \\
\hline Normal saline & 50.0 & 0.50 \\
\hline $\begin{array}{l}\text { Gauze (8 small packs): Dressing pack with } \\
\text { gauze, strapping, lodine }\end{array}$ & 50.0 & 0.50 \\
\hline Total cost & 100.0 & 1.00 \\
\hline \multicolumn{3}{|l|}{ Vinegar dressing } \\
\hline Normal saline $(500 \mathrm{~mL})$ & 50.0 & 0.50 \\
\hline $\begin{array}{l}\text { Gauze (8 small packs): dressing pack with } \\
\text { gauze, strapping }\end{array}$ & 50.0 & 0.50 \\
\hline Vinegar & 90.0 & 0.90 \\
\hline Total cost & 190.0 & 1.90 \\
\hline
\end{tabular}

the wound bed. In addition, the intermittent low pressure alters the structure of the cells in the wound area, which then triggers an inflammatory and proliferative cascade that increases the rate of formation of granulation tissue (6). The technique has been in use for about 30 years (10). In MCRH, the improvised NPWT worked effectively in aiding wound healing despite the limitations surrounding the technique. In the ideal set up, a fitting foam dressing is first cut and placed gently over the wound and a draining tube is the placed above the dressing. This dressing is finally covered with adhesive transparent tape (11). In the present study, the foam was substituted with the layers of gauze (12). Most foam dressings are laced with antibiotics, but a modification in the results presented here used honey dressing. In addition, the cling film and urine bag tubing substituted transparent adhesive tape and the drain system, respectively. Fluid in the wound was suctioned by the modified foam into a disposable canister in the negative pressure unit, a suction machine canister in the present study. The dressings were changed every 48 hours, and where an existing wound was infected or electric power fluctuated, every 24 hours. The results presented here showed no infection or accumulation of pus after 24 or 48 hours. These results were consistent with previous observations that showed the dressing may be required for 2-6 weeks, depending on the wound type and the rate of wound healing (13).

The disadvantages of NPWT technique include the need to be connected to a machine for at least 22 hours in a day and initial pain from applying pressure. Potential complications that may arise that warrant discontinuation of the therapy include tubing pressure necrosis, injury to the adjoining skin, growth of granulation tissue within the strands of the foam dressing, contact dermatitis due to the adhesive tape, formation of fistulas and, in rare cases, skin cancer due to increased blood flow in the wound bed (14).

A previous analysis of treatment showed the cost for a fully functional NPWT to the patient is approximately USD 180 weekly excluding the re-usable NPWT system. Another study places the cost at USD 119,224 per 1,000 days (14). On the contrary, the cost incurred by the patients on improvised NPWT in MCRH was KES 360.00 (USD 3.60) per week (Table 2). This is comparatively more cost effective and can be achieved especially in resource-limited settings.

Honey has been used in wound therapy for several decades. Recent studies have shown that honey has an inhibitory effect on approximately 60 bacteria species and acts against aerobes and anaerobes (15). In addition, it has antifungal action against Aspergillus species, yeast and dermatophytes (16). Manuka honey, produced in New Zealand, contains rich chemical ingredients that have, among others, antioxidant effects that aid in rapid wound healing and faster tissue regeneration (15).

The advantages of honey include a high osmotic effect on wounds, which inhibits microbial growth, allowing creation of a perfect osmotic gradient that would mop up exudate from the wound, enabling faster healing. In addition, the sugar content including fructose (40\%), glucose (30\%) and 5\% sucrose provides sufficient substrate for microorganisms and therefore prevents them from obtaining substrates directly from the wound site, effectively decreasing formation of bacterial biofilms (17). Honey contains an enzyme, Inhibin, that yields small quantities of hydrogen peroxide. The hydrogen peroxide concentration in honey is 1000 times less than in the $3 \%$ solution commonly used as an antiseptic (20). Honey's low $\mathrm{pH}$ inhibits the growth of bacteria, and its components provide an antioxidant effect $(18,19)$. Previous studies have associated honey with increased phagocytic and lymphocytic activity on a wound (17). 
In the current study, pure natural honey was used. Although no comparative studies on the cost of using honey in wound care were obtained, total cost incurred by the patient was KES 225.00 (USD 2.25) per week.

Wound debridement and irrigation with normal saline form a critical step in wound healing. This is because normal saline enables rapid progression from the inflammatory to proliferative phase of wound healing by removing debris that can negatively affect the entire healing process. Irrigation, especially with higher pressures, helps prevent premature surface healing above an infected tract or an abscess pocket (20).

Other solutions used as irrigants include topical cleansers, antibiotics, antifungals, antiseptics and anesthetics. However, antiseptic solutions such as povidone-iodine, chlorhexidine, and hydrogen peroxide have been shown to be toxic to tissues and may negatively affect acute wound healing (19).

We estimated the cost incurred by patients who required irrigation with normal saline and dressing with sterile gauze to be approximately KES 100.00 (USD 1.00) per week. No comparative studies on the cost were obtained.

Iodine has been used for wound cleaning for a long time. However, it is currently being phased out globally because studies have associated it with tissue necrosis (20). Despite this effect, iodine is still used for debriding wounds, preventing infection on new wound surfaces, and promoting wound healing by activating monocytes and macrophages. Of the two types commercially available, povidone-iodine is frequently used because of its positive effect on growth of fibroblasts which boost regeneration of the wound (9). The cost incurred using this procedure was approximately KES 100 (USD 1) per week at MCRH. This cost was similar to the cost of irrigating with normal saline because the dressing pack comes with iodine and the clinician decides whether to use it.

Recent studies on vinegar use on wounds have demonstrated presence of several antimicrobial properties that include inhibiting growth of group D Enterococcus, Staphylococcus aureus, Escherichia coli and Pseudomonas aeruginosa, reducing the amount of bacterial biofilm present on the surface of the wound. The bactericidal acetic acid present in vinegar helps minimize chances of infection and accelerates the rate of wound healing (7).

Vinegar must first be diluted to prevent toxicity to the tissues. The procedure requires initially debriding the wound, diluting the vinegar with normal saline at a ratio of $1: 2$, and then applying it to the wound surface. Vinegar has been shown to slow wound healing but it was not possible to evaluate this quality in this study. In addition, applying honey and vinegar concurrently was not practiced in MCRH, although previous studies have shown effectiveness in alleviating pain and increased antimicrobial activity (7). The total cost per week of using normal saline irrigation and vinegar application on a wound was KES 190 (USD 1.90). We recommend larger follow-up studies, incorporating chronic wounds, to quantify the wound healing rates as well as wound care costs using the techniques we have observed. Such local wound care products should be availed to healthcare providers to expand the choices in wound management.

\section{Conclusion}

The different wound dressing techniques used in MCRH were shown to be effective, efficient and cost effective. They are easy to perform (including modified NPWT) and can easily be incorporated into resource-constrained health settings with good outcomes.

\section{Acknowledgements}

I am extremely grateful to Dr. Bonuke Anyona, Dr. Caesar Bitta and Dr. Amos Oyoko from Maseno University who read the final draft and proposed critical suggestions and corrections.

\section{References}

1. National Bureau of Statistics. Kenya Population and Housing Statistics. 2009; (7)

2. Solis-Tellez H, Mondragon-Pinzon EE, Ramirez-Marino M, et al. Epidemiologic analysis: prophylaxis and multidrugresistance in surgery. Rev Gastroenterol Mex. 2017; 82(2):11522.

3. Boateng JS, Matthews KH, Stevens HN et al. Wound healing dressings and drug delivery systems: a review. J Pharm Sciences. 2008; 97(8):2892-923.

4. Back DA, Scheuermann-Poley C, Willy C. Recommendations on negative pressure wound therapy with instillation and antimicrobial solutions - when, where and how to use: What does the evidence show? Int Wound J. 2013; 10Suppl 1:32-42.

5. Isaac AMA-K, Salim ME, Ahmed IA-RM. An affordable custom-built negative pressure wound therapy. Ann Afri Surg. 2017; 14(1).

6. Barnea Y, Weiss J, Gur E. A review of the applications of the hydrofiber dressing with silver (Aquacel $\mathrm{Ag} \AA$ ) in wound care. Therapeutics and Clin Risk Man. 2010; 6:21.

7. Johnston CS, Gaas CA. Vinegar: Medicinal uses and antiglycemic effect. Med Gen Med. 2006; 8(2):61.

8. Borgquist O. Negative pressure wound therapy: Therapy settings and biological effects in peripheral wounds. Lund University; 2013.

9. Steinhoff G. Regenerative Medicine. Steinhoff G, editor: Springer Netherlands; 2011. XXIV, 1032 p

10. Othman D. Negative pressure wound therapy. Literature review of efficacy, cost effectiveness, and impact on patients' quality 
of life in chronic wound management and its implementation in the United Kingdom. Plast Surg Int. 2012; 2012:6.

11. Rhee SM, Valle MF, Wilson LM, et al. Negative pressure wound therapy technologies for chronic wound care in the home setting: A systematic review. Wound Repair Regen. 2015; 23(4):506-17.

12. Kairinos N. The biomechanics of negative-pressure wound therapy. Doctoral dissertation, University of Cape Town. 2011

13. Baranoski S, Ayello EA. Wound care essentials: Practice principles: Lippincott Williams \& Wilkins; 2008.

14. Bullough L. Negative pressure wound therapy treatment costs - a comparative evaluation. In press, 2015.

15. Niaz K, Maqbool F, Bahadar H, et al. Health benefits of manuka honey as an essential constituent for tissue regeneration. Curr Drug Metab. 2017.

16. Boukraâ L. Honey in traditional and modern medicine: CRC Press; 2013.
17. Nwankwo C, Ezekoye CO, Igbokwe S. Phytochemical screening and antimicrobial activity of apiary honey produced by honey bee (Apis mellifera) on clinical strains of Staphylococcus Aureus, Escherichia coli and Candida albicans. 2014; 2367-72.

18. Kotsirilos V, Vitetta L, Sali A. A guide to evidence-based integrative and complementary medicine. 1st ed. 2010 ed. Elsevier Australia: National Herbalists Association of Australia; 2011.

19. Sussman C, Bates-Jensen BM. Wound care: A collaborative practice manual. Wolters Kluwer Health / Lippincott Williams \& Wilkins; 2007.

20. Singer AJ, Hollander JE, Blumm RM. Skin and soft tissue injuries and infections: A practical evidence based guide. Shelton, CT: People's Medical Pub. House-USA; 2010. 